\title{
Detection of Lung Affections of Stray Cats in Mosul City, Iraq
}

\author{
Karam Hashim Al-Mallah and Mohamed Ghassan Saeed* \\ Department of Pathology and Poultry Diseases, College of Veterinary Medicine, University of Mosul, Mosul, Iraq \\ *Corresponding author’s E-mail: mohamad.ghassan.@yahoo.com; (DORCiD: 0000-0002-9433-8293
}

\begin{abstract}
Stray cats are exposed to deleterious factors in the urban environment. The present study was aimed to describe the pathological features of lung lesions in stray cats in Mosul city, Iraq. From February to March 2013, 19 ailing cats were caught through animal control campaigns and euthanized. Necropsy and histopathologic findings were recorded for the collected lungs. The results indicated lesions in all the lung samples. Pathomorphogical characterization included emphysema (84\%), atelectasis (63\%), and bronchiectasis (26\%), bronchopneumonia $(63 \%)$, granulomatous pneumonia $(15 \%)$, verminous pneumonia $(15 \%)$, alveolitis $(15 \%)$, proliferative pneumonia $(10 \%)$, and pleuropneumonia (5\%). In addition, cellular adaptation was characterized by hyperplasia of alveolar cells (52\%), bronchial epithelium hyperplasia (31\%) and fibroplasia (26\%). Hemosiderosis and parasitic infestation were also detected. The study concluded that all lungs collected from stray cats showed pathological changes, reflecting the presence of the pathogen agents and pollution in the environment of this city.
\end{abstract}

Keywords: Mosul city, Lesions, Lung, Pneumonia, Stray cats

\section{INTRODUCTION}

Stray cats may live in environmentally polluted areas, thus the feline respiratory system is exposed to smoke, toxic gases, dust, disinfectants, chemicals and oil derivatives (Bao et al., 2018). These cats are susceptible to infection with biological agents such as bacteria, viruses, parasites, and fungi. Also trauma caused by being hit by a car or beating may lead to lung disorders (Bates and Smith, 2018).

Lung reacts against such agents by mucus production, constriction, and airway swelling, followed by an inflammatory response in the lungs known as pneumonia (Mohammed et al., 2017). Lung dysfunction develops in most cats in the within the first two or three days after exposure. Invasion of opportunistic bacterial infections may be a common cause of death in the late stages of disease (Lopez and Martinson, 2017).

A variety of bacterial, viral, parasitic and fungal organisms can cause pneumonia in cats. Viruses such as feline herpesvirus-1, feline calicivirus (Monne et al., 2018) and H1N1 influenza virus (Löhr et al., 2010) are viral common causes of respiratory infection. There are many bacteria cause pneumonia such as Escherichia coli, Klebsiella spp., Pasteurella spp., Staphylococcus spp., and Bordetella bronchiseptica (Dear, 2014; Lee-Fowler, 2014). Parasitic pneumonia in cats can be caused by a number of parasites that are defined as lungworms. Aelurostrongylus abstrusus is the most well-known feline lungworm and is the most prevalent in domestic cats (Elsheikha et al., 2016; Giannelli et al., 2017). Also Toxoplasma gondii (Jalil and Alwan, 2014) and the fungus Cryptococcus may cause pneumonia (Pimenta et al., 2015).

Aspiration pneumonia in cats occurs due to the inhalation of foreign bodies, vomit, or the regurgitation of gastric contents. Also, it can be a result of a neuromuscular disorder causing difficulty in the swallowing, and paralysis of esophagus. Bacteria present in the inhaled foreign matter may also bring about infection (Giannelli et al., 2017; BarreraZarate et al., 2018). Sometimes, a secondary bacterial infection follows the viral or fungal infection which causes damage to the lung, thus pneumonia can be caused by more than single organism. The present study aimed to describe the pathological changes of lungs of stray cats in Mosul city. Iraq.

\section{MATERIALS AND METHODS}

\section{Ethical approval}

This experiment was conducted according to the rules of the Research Ethics Committee of College of Veterinary Medicine, University of Mosul, Iraq. 


\section{Experimental design}

Nineteen mature ailing and depressed stray cats (aged 1-3 years of either sex) were caught through bulk animals control campaign in Mosul city, Iraq from February to March 2013. The animals were kept in cages, and then euthanized by a single dose of subcutaneous injection of insulin / (Novo nordisck / France) at 60 IU (Niessen et al., 2017). Necropsy was performed and gross pathological changes were recorded and photographed. The lungs samples were preserved in $10 \%$ neutral buffered formalin, then trimming, dehydration, clearing, paraffine embedding, sectioning, hematoxylin and eosin staining, and DPX mounting were performed (Luna, 1968). Lung sections were examined under light microscope (OPTIKA, Italy), photographed by a digital camera (Samsung/ South Korea) and the histopathological changes were recorded.

\section{RESULTS}

In this study, all examined samples was pathologically affected and had a wide variety of lesions with varying degrees of severity, including cell adaptations manifested by hyperplastic alveolar cells, hyperplastic bronchial epithelium cells, and intralobular fibroplasia which appeared in $52.63 \%, 31.57 \%$ and $26.31 \%$ of samples, respectively (Table 1, figure 1A, $\mathrm{C}$ and D). Disturbances in cell metabolism and cell death were also observed as hyalinization of alveolar walls, intrabronchiolar hyaline casts, necrotic bronchiolar submucosal glands and bronchiolar mucinous degeneration at incidence rates of $5.26 \%, 10.52 \%, 10.52 \%$ and $36.84 \%$, respectively (Table 1, figure $1 \mathrm{C}$ and $\mathrm{D}$, figure $2 \mathrm{~A}$ and $\mathrm{B}$ ).

Circulatory disturbances and vascular affections included vascular hyperaemia, pulmonary haemorrhage, and pulmonary edema at an incidence rate of $21.05 \%$ each as well as atherosclerosis at $10.52 \%$ of the total samples (Table 1 , figures $2 \mathrm{C}$ and figure 4A). Morpho-mechanical alterations in pulmonary tissue were also recorded as bronchiectasis (26.31\%), alveolar emphysema $(84.21 \%$ ) and alveolar atelectasis in $63.15 \%$ of the examined lungs (Table 1, figure $3 \mathrm{~A}$ and B). The chronic inflammation was the most frequently change at all examined sections, which appeared as chronic pleuropneumonia (5.26\%), chronic bronchopneumonia (63.15\%), granulomatous pneumonia (15.78\%), proliferative pneumonia (10.52\%) and verminous pneumonia (15.78\%) (Table 1, figure $1 \mathrm{~B}$, figure $3 \mathrm{C}$ and $\mathrm{D}$, figure $4 \mathrm{~A}, \mathrm{~B}, \mathrm{C}$, and $\mathrm{D}$ ), which contained different types of exudates including fibrinous, fibrinopurulent and lymphocytic exudates (Figures 4B, $\mathrm{C}$ and $\mathrm{D}$, figure $5 \mathrm{~A}$ ). Alveolitis and bronchiolitis obliterans were also found each in $15.78 \%$ of examined samples (Table 1 , figures $5 \mathrm{~A}$ and $\mathrm{B}$ ). The examination also revealed parasitic infestation with metastrongyloid lungworms in $15.78 \%$ of samples (Table 1, figure 4C and D). Disturbances of pigmentation were charechterized by hemosiderosis and presence of heart failure cells at incidence rates of 5.26\% and 21.05\%, respectively (Table 1 and Figure 5C).

Table 1. Pathological categorization and incidence rate of lung lesions monitored in stray cats in Mosul city, Iraq

\begin{tabular}{|c|c|c|c|}
\hline Pathological categorization & Lesion & $\begin{array}{c}\text { Number of affected } \\
\text { samples }\end{array}$ & Incidence rate \\
\hline \multirow{3}{*}{ Cell adaptations } & Hyperplastic alveolar cells & 10 & $52.63 \%$ \\
\hline & Hyperplastic bronchial epithelium & 6 & $31.57 \%$ \\
\hline & Intralobular fibroplasia & 5 & $26.31 \%$ \\
\hline \multirow{4}{*}{$\begin{array}{l}\text { Disturbances in cell metabolism and } \\
\text { cell death }\end{array}$} & Hyalinization of alveoli & 1 & $5.26 \%$ \\
\hline & Intrabronchiolar Hyaline cast & 2 & $10.52 \%$ \\
\hline & Necrotic bronchial submucosal glands & 2 & $10.52 \%$ \\
\hline & Bronchiolar mucinous degeneration & 7 & $36.84 \%$ \\
\hline \multirow{4}{*}{$\begin{array}{l}\text { Circulatory disturbances and vascular } \\
\text { affections }\end{array}$} & Hyperemia & 4 & $21.05 \%$ \\
\hline & Pulmonary hemorrhage & 4 & $21.05 \%$ \\
\hline & Pulmonary edema & 4 & $21.05 \%$ \\
\hline & Atherosclerosis & 2 & $10.52 \%$ \\
\hline \multirow{3}{*}{ Morphomechanical alterations } & Bronchiectasis & 5 & $26.31 \%$ \\
\hline & Emphysema & 16 & $84.21 \%$ \\
\hline & Atelectasis & 12 & $63.15 \%$ \\
\hline \multirow{7}{*}{ Inflammation and repair } & Chronic pleuropneumonia & 1 & $5.26 \%$ \\
\hline & Chronic bronchopneumonia & 12 & $63.15 \%$ \\
\hline & Granulomatous pneumonia & 3 & $15.78 \%$ \\
\hline & Proliferative pneumonia & 2 & $10.52 \%$ \\
\hline & Verminous pneumonia & 3 & $15.78 \%$ \\
\hline & Alveolitis & 3 & $15.78 \%$ \\
\hline & Bronchiolitis obliterans & 3 & $15.78 \%$ \\
\hline Parasitic infestation & Pulmonary nematodiasis & 3 & $15.78 \%$ \\
\hline \multirow{2}{*}{ Disturbances of pigmentation } & Hemosiderosis & 1 & $5.26 \%$ \\
\hline & Heart failure cells & 4 & $21.05 \%$ \\
\hline
\end{tabular}




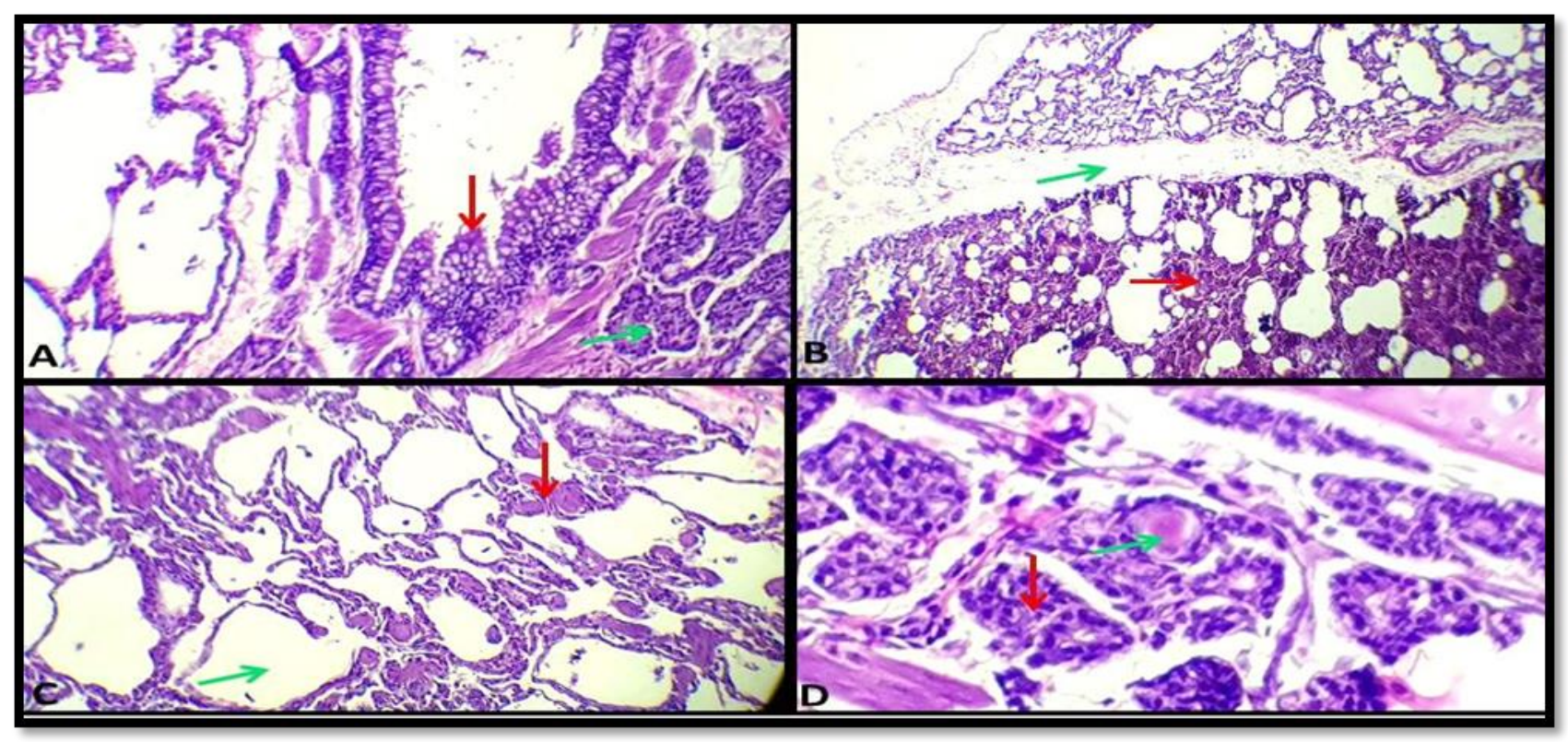

Figure 1. Photomicrograph of a cat lung section. A: Hyperplasia and mucinous degeneration of bronchial epithelium (red arrow) and hyperplastic submucosal glands (green arrow), 265X. B: Chronic proliferative pneumonia (red arrow) and intralobular septal fibroplasia (green arrow), 165X. C: Hyalinization of alveolar walls and emphysema (red arrow), 145X. D: Hyperplastic bronchial glands (red arrow) with hyaline casts (green arrow), 450X. H\&E staining was used for all photomicrographs.

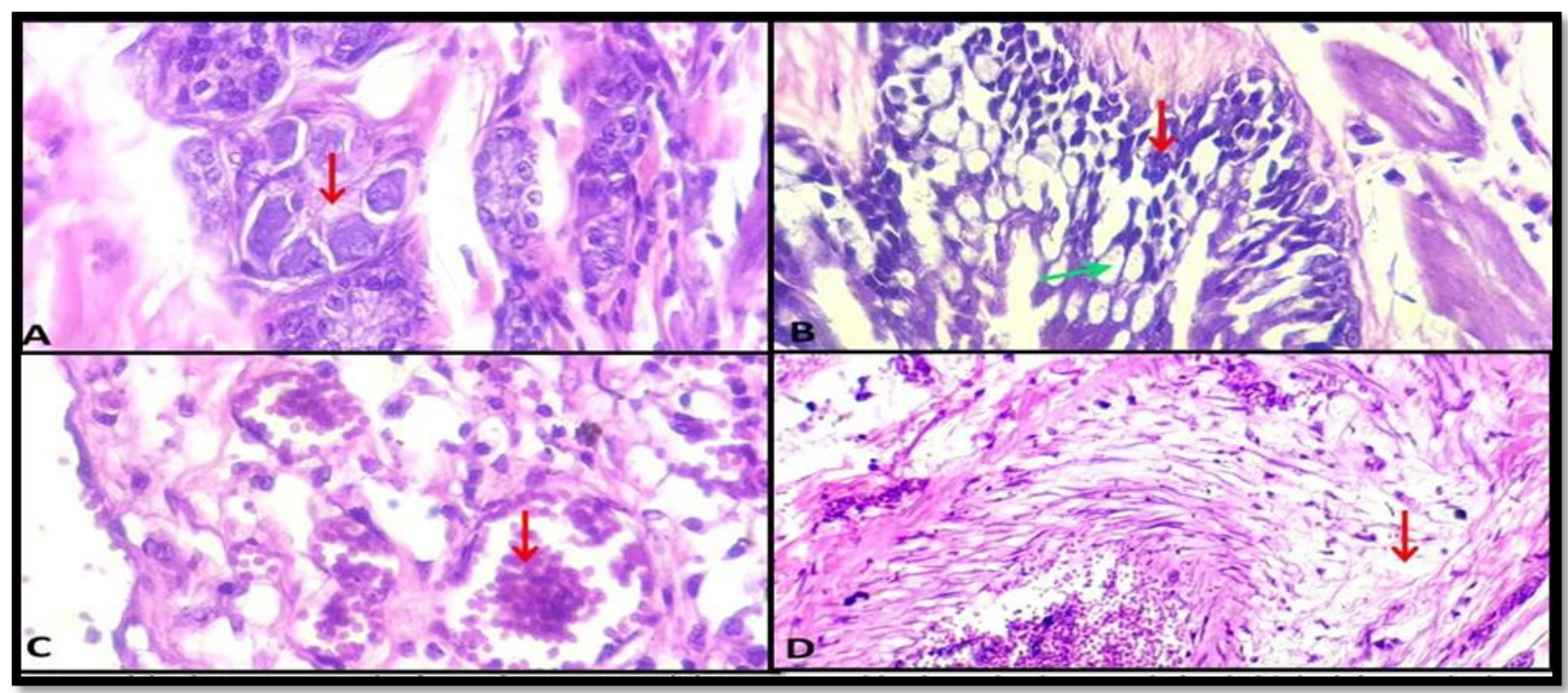

Figure 2. Photomicrograph of a cat lung section. A: Necrotic and hyalinized submucosal glands (red arrow), $560 \mathrm{X}$. B: Bronchiolar hyperplasia (red arrow) and mucinous degeneration (green arrow), 450X. C: Pulmonary hemorrhage (red arrow), 560X. D: Atherosclerotic artery (red arrow), 200X. H\&E staining was used for all photomicrographs. 


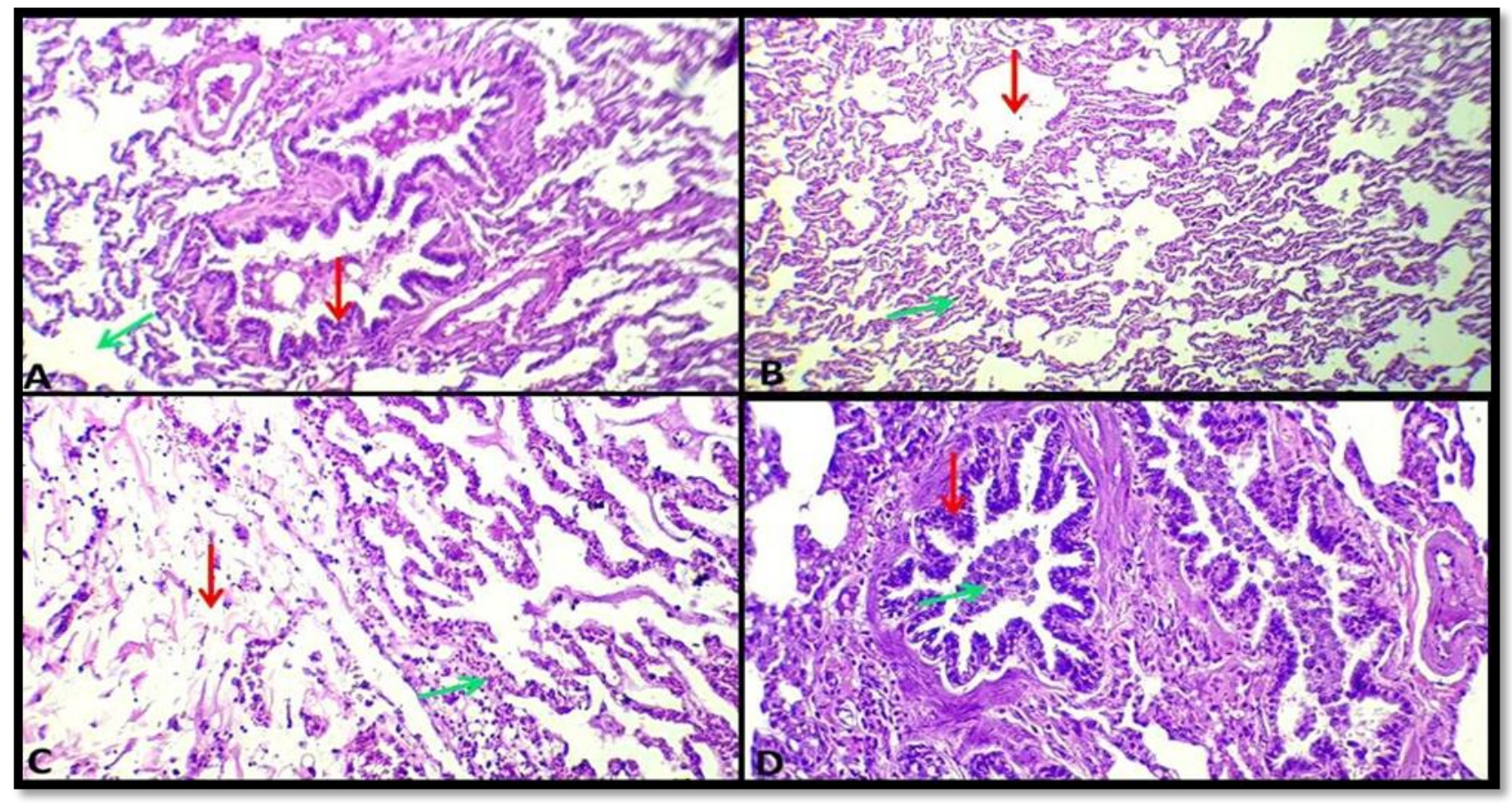

Figure 3. Photomicrograph of a cat lung section. A: Bronchiectasis (red arrow) and emphysema (green arrow) with exudate in the lumen, 100X. B: Emphysema (red arrow) and atelectasis (green arrow), 56X. C: Chronic pleuropneumonia as pleurisy (red arrow) and pneumonia (green arrow), 240X. D: Chronic bronchopneumonia as bronchitis with bronchial lumen filled with exudate (red arrow) and inflammatory cells infiltrations (green arrow) with in pulmonary parenchyma, 280X. H\&E staining was used for all photomicrographs.

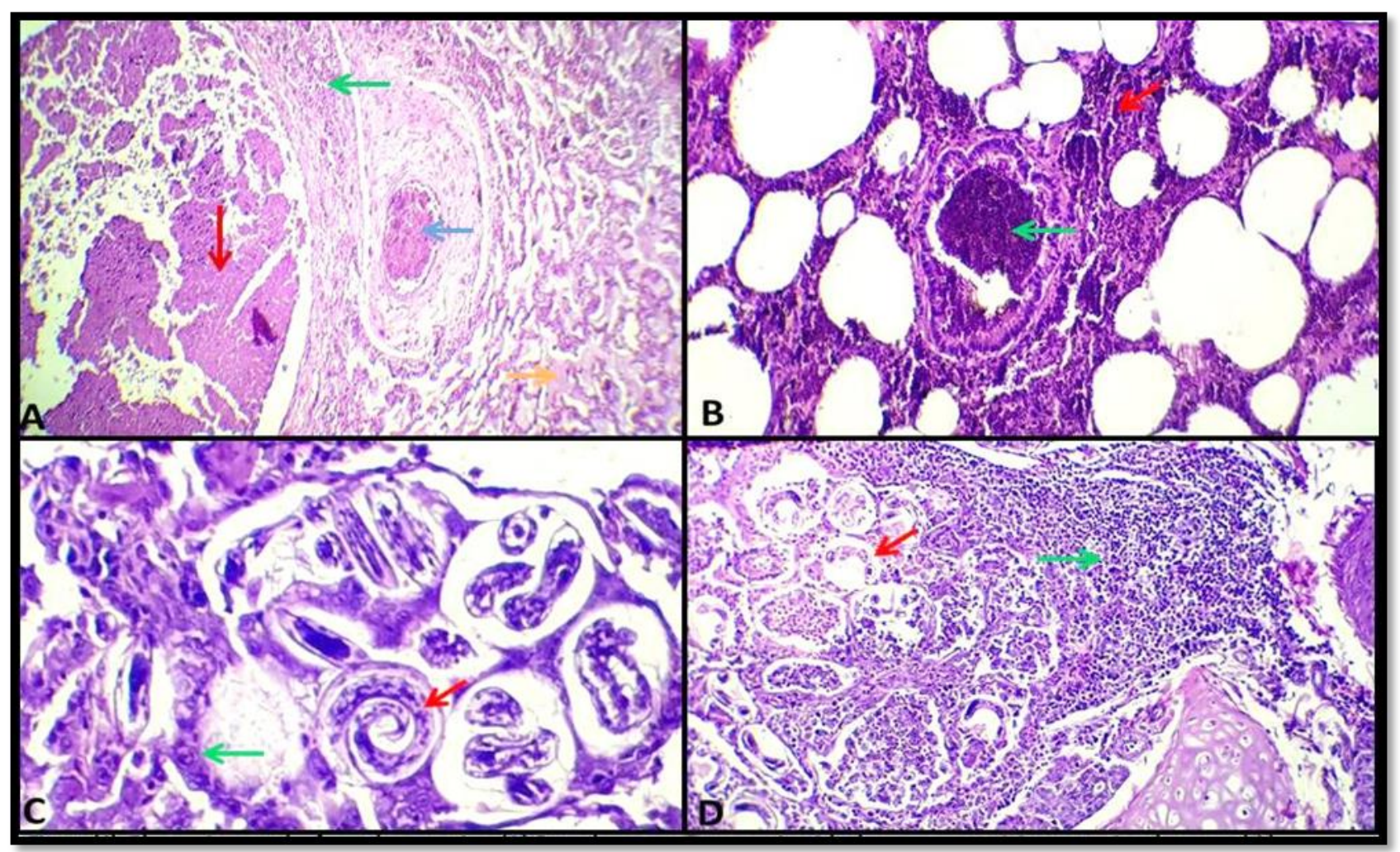

Figure 4. Photomicrograph of a cat lung section. A: Granulomatous pneumonia with abscesses containing necrotic substances (red arrow) surrounding by granulomatous reaction (green arrow) hyperemic blood vessels (blue arrow) and pulmonary edema (yellow arrow), 40X. B: Proliferative bronchopneumonia (red arrow) with accumulation of exudate in bronchi (red arrow), 145X. C: Verminous pneumonia reflecting pulmonary nematodiasis (red arrow) and alveolitis (green arrow), 780X. D: Verminous (red arrow) and proliferative pneumonia (red arrow), 115X. H\&E staining was used for all photomicrographs. 


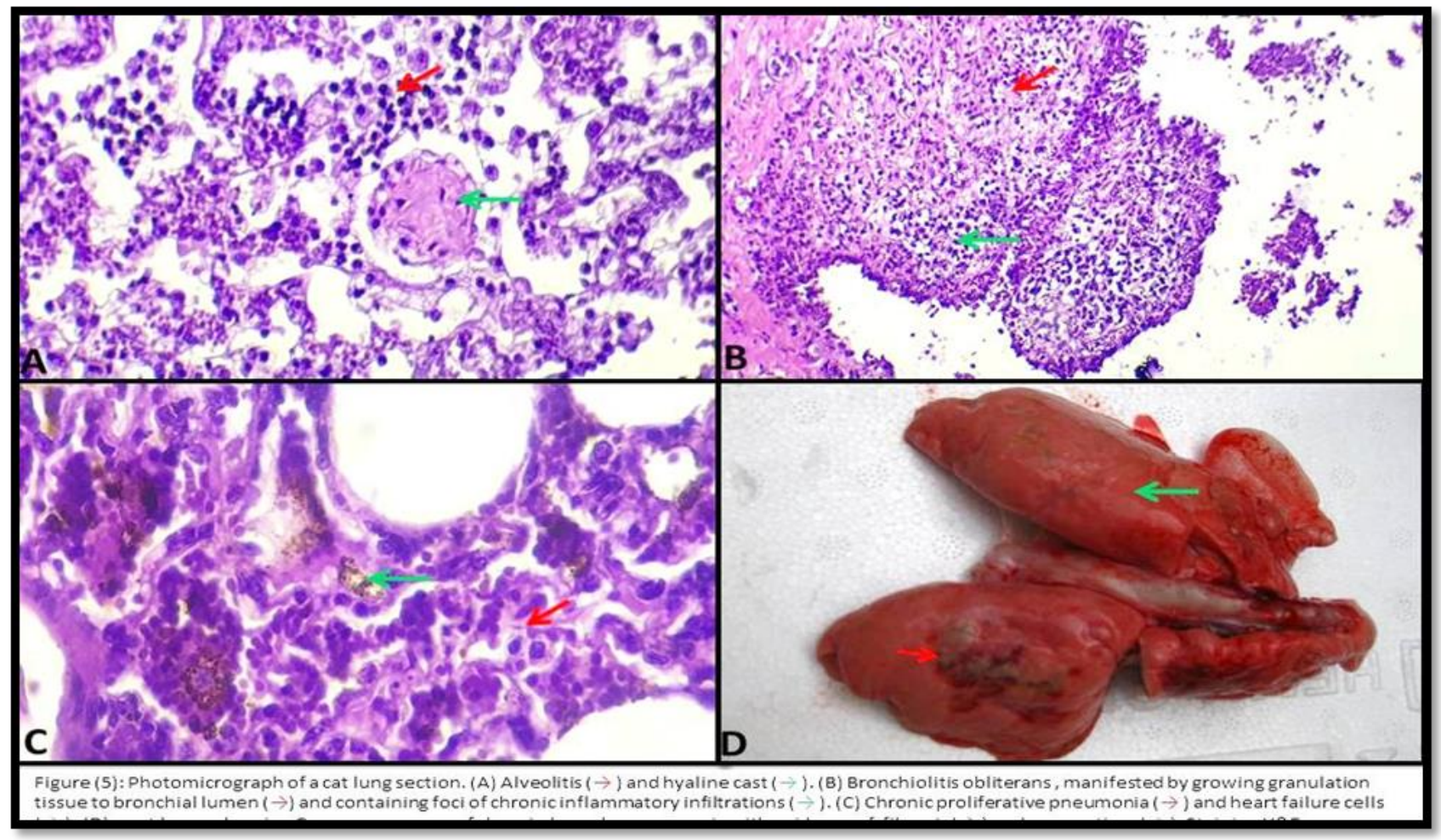

Figure 5. Photomicrograph of a cat lung section. A: Alveolitis (red arrow) and hyaline cast (green arrow), 370X. B: Bronchiolitis obliterans, manifested by growing granulation tissue to bronchial lumen (red arrow) and containing foci of chronic inflammatory infiltrations (green arrow), 165X. C: Chronic proliferative pneumonia (red arrow) and heart failure cells (green arrow), 450X. D: Cat lungs shows gross appearance of chronic bronchopneumonia with fibrosis (green arrow) and congestion (red arrow ). H\&E staining was used for all photomicrographs.

\section{DISCUSSION}

The present study investigated the prevalence of pathological changes in the lungs of a stray cat population in Mosul, Iraq. This study was the first study conducted in Iraq on pathological changes of lungs of cats. Different types of lesions with various severity appeared in the collected lungs. This may be due to the individual variation of defense mechanism and immune system in cats, in addition to the difference in type of causative agents and duration of exposure to those.

Normally, many bacteria live in the feline respiratory system, without causing disorders, but can cause disease when respiratory defense mechanisms overwhelmed by viral infections such as rhinotracheitis virus, influenza A virus and calicivirus, or a systemic disease such as congestive heart failure, diabetes mellitus, lung tumors or irritants such as smoke and noxious gases (Mexas et al., 2006; Dorn et al., 2017; Arsevska et al., 2018).

The results indicated the chronic pneumonia of all types in highest incidence especially chronic bronchopneumonia. $63.15 \%$ of the examined lungs may be affected by aerosol rout that cat inhaled foreign bodies into its lungs like a tiny piece of plastic or a seed pod. Also vomitting and regurgitation could irritate the lung tissue and cause pneumonia (Thawley and Drobatz, 2015; Barrera-Zarate et al., 2018). The vomited or external materials may contain pathogens such as Chlamydophila (psittaci) felis, Bordetella bronchiseptica, Pasteurella spp., Moraxella spp., (Foster et al., 2004) and feline herpesvirus-1 (McGregor et al., 2016), which cause bronchopneumonia characterized by neutrophilic bronchiolitis, infiltration of neutrophils and mononuclear cells, and thickening of the alveolar walls by edema and hyperplasia (Lopez and Martinson, 2017). Löhr et al. (2010) mentioned that infection with influenza A virus (H1N1) in cats cause pyonecrotizing bronchointerstitial pneumonia which accompanied by serofibrinous exudate in the alveoli and hyalinization, and secondary bacterial multiplications (Sykes, 2013). These lesions are similar to those observed in the present study.

In general, pneumonia occurs in immunosuppressive cats and it is usually accompanied by secondary morphomechanical alterations including bronchiectasis, alveolar emphysema and alveolar atelectasis. Bronchiectasis is a consequence of chronic bronchitis due to accumulation of inflammatory exudates in the lumen and partial ruptures of bronchial walls or as a result of bronchiolitis obliterans (Nelson and Couto, 2008; Maxie, 2016).

Emphysema is always secondary to obstruction of outflow of air which frequently occurs in carnivorous with bronchopneumonia and characterized by distention and rupture of alveolar walls. While the two main causes of compressive atelectasis are related to the transferred pressures or space-occupying masses in the pleural cavity or it accompanies with chronic pleuropneumonia. Many viruses infect respiratory system of cats and may cause pneumonia. Bayati and Akaby (2017) reported that feline panleukopenia virus cause pleuropneumonia and proliferative pneumonia. 
Other studies indicated the role of feline herpesvirus type 1, feline calicivirus and feline coronavirus in pneumonia as the consequence of spreading the virus from the upper respiratory airways into the lungs, where they cause virus-induced lesions charcterized by marked neutrophil infiltration and extensive necrosis (Balboni et al., 2014; Monne Rodriguez et al., 2018). Atelectasis is also occur when the lumen of the airways is blocked by mucus substance and inflammatory exudate (Maxie, 2016). Furthermore, granulomatous pneumonia was detected at incidence rate of $15.78 \%$. It is commonly caused by the fungus Cryptococcus neoformans or it may be caused by Mycobacterium thermoresistibile (Foster et al., 1999). It occurs in immunosuppressive cats due to viral infections and malnutrition, and are represented grossly by small gelatinous white foci (Trivedi et al., 2011).

The circulatory disturbances (hyperemia, hemorrhage and pulmonary edema) occurred concomitantly to pneumonia or principally injury to pulmonary vessels (Monne Rodriguez et al., 2018). Pulmonary edema is frequently associated with pneumonia and also it may be caused by anemia, congestive heart failure, hypoproteinemia, corrosive gasses and toxic vapors such as smoke and endotoxin (Balboni et al., 2014).

Cell adaptations occur constantly as a response to chronic injury, stress and irritant (Monne Rodriguez et al., 2018). Hyperplasia is the most common change associated with chronic pneumonia; hyperplastic alveolar cells are obseverd in alveolitis and hyperplastic bronchial cells are usually observed in bronchopneumonia (Wallig et al., 2017). Chronic proliferative pneumonia may lead to pulmonary fibroplasia (White et al., 2003) charachterized by thickened lungs with proliferating connective tissue of alveolar wall, formation of hyaline membranes, and alveolar cells hyperplasia (Bruminhent et al., 2011). Formation of hyaline membranes and cast result from leakage of excessive plasma proteins and fibrinous exudate into alveoli with necrosis of type I pneumonocytes and pulmonary surfactant. Hyalinization is present in interstitial pneumonia, emphysema and edema and alveolitis (Kennedy and Palmer, 2013; Monne Rodriguez et al., 2018).

Verminous pneumonias was detected in the present study which can be caused by a number of parasitic nematodes, but metastrongyloid worms considered as the most common lungworms (Elsheikha et al., 2016). It was assumed that the causative parasite of pneumonia in this study may be Aelurostrongylus abstrusus which is the most common feline lungworm in domestic cats. It may remain in the lung as chronic disease accompanying by secondary bacterial infections. The parasites and their eggs and larvaes in the bronchioles and alveoli have been seen in this study where they caused bronchiolitis and alveolitis and alveolar fibrosis as reported in previous studies (Bowman, 2000; Giannelli et al., 2017).

Mexas et al. (2006) suggested that the incidence of respiratory infections in cats associated with diabetes mellitus. They referred to the correlation between diabetes mellitus and abnormal pulmonary lesions which included pneumonia, edema, histiocytosis, fibrosis, smooth muscle hypertrophy, mineralization, and neoplasia.

\section{CONCLUSION}

In this study, all the lungs collected revealed pathological changes that indicate the poor health status of the stray cats and the pollution in the environment of Mosul city in Iraq.

\section{DECLARATIONS}

\section{Acknowledgments}

We would like to thank the College of Veterinary Medicine, University of Mosul for supporting this work.

\section{Authors' contributions}

Both authors contributed equally to this work and checked the final edition of article for publication in World`s Veterinary Journal.

\section{Competing interests}

The authors declare that they have no conflict of interest.

\section{REFERENCES}

Arsevska E, Priestnall SL, Singleton DA, Jones PH, Smyth S, Brant B, Dawson S, Sánchez-Vizcaíno F, Noble PJM and Radford AD (2018). Small animal disease surveillance: respiratory disease 2017 Veterinary Record, 182: 369-373. Available at: https://research-information.bristol.ac.uk.

Balboni A, Bassi P, Battilani M, Biserni R, Prosperi S and Dondi F (2014). Severe, diffuse fibrinonecrotic pleuropneumonia in a cat affected by multiple viral infection. Veterinaria Italiana, 50(2): 145-149. DOI: https://doi.org/10.12834/VetIt.49.144.2.

Bao M, Huo L, Wu J, Ge D, Lv Z, Chi C and Liu H (2018). A novel biomarker for marine environmental pollution of CAT from Mytilus coruscus. Marine Pollution Bulletin, 127: 717-725. DOI: https://doi.org/10.1016/j.marpolbul.2018.01.003. 
Barrera-Zarate JA Paiva BA, Ferreira DP, Alves FS, Sato JPH and Guedes RMC (2018). Barium sulphate aspiration pneumonia in a cat with megaesophagus and dextroposition of the aortic arch: case report. Arquivo Brasileiro de Medicina Veterinária e Zootecnia, 70(5): 1453-1458. DOI:https://doi.org/10.1590/1678-4162-10059.

Bates J and Smith BJ (2018). Ventilator-induced lung injury and lung mechanics. Annals of translational medicine, 6(19): 378. DOI: https://doi.org/10.21037/atm.2018.06.29.

Bayati HAA and Akaby SRA (2017). Study of histopathological changes associated with feline pan leukopenia virus infection in naturally infected cats. Journal of College of Education / Wasit University, 1(26): 511-520. DOI:https://doi.org/10.31185/eduj.vol1.iss26.106.

Bowman DD (2000). Respiratory system parasites of the dog and cat (part ii): trachea and bronchi, and pulmonary vessels. In: Companion and exotic animal parasitology. International Veterinary Information Service. Available at: https://pdfs.semanticscholar.org/d69a/d0aa9e55ec120bdbe9dad68cc38bf0cfec7b.pdf

Bruminhent J, Yassir S and Pippim J (2011). Acute interstitial pneumonia (hamman-rich syndrome) as a cause of idiopathic acute respiratory distress syndrome. Case Reports in Medicine, 2011: 628743. DOI:https://doi.org/10.1155/2011/628743

Dear JD (2014). Bacterial pneumonia in dogs and cats. veterinary clinics of north america small animal practice, 44(1):143-159. DOI:https://doi.org/10.1016/b978-0-7216-8706-3.50060-8

Dorn ES, Tress B, Suchodolski JS, Nisar T, Ravindran P, Weber K, Hartmann K and SchulzBS (2017). Bacterial microbiome in the nose of healthy cats and in cats with nasal disease. PLoS One, 12(6):e0180299. DOI:https://doi.org/10.1371/journal.pone.0180299

Elsheikha HM, Schnyder M, Traversa D, Di Cesare A, Wright I and Lacher DW (2016). Updates on feline aelurostrongylosis and research priorities for the next decade. Parasites and Vectors, 9(1): 389. DOI:https://doi.org/10.1186/s13071-016-1671-6

Foster SF, Martin P, Allan GS, Barrs VR and Malik R (2004). Lower respiratory tract infections in cats: 21 cases (1995-2000). Journal of Feline Medicine and Surgery, 6, 3:167-180. DOI: https://doi.org/10.1016/j.jfms.2003.11.006

Foster SF, Martin P, Davis W, Allan GS, Mitchell DH and Malik R (1999). Chronic pneumonia caused by Mycobacterium thermoresistibile in a cat. Journal of Small Animal Practice, 40(9): 433-438. DOI: https://doi.org/10.1111/j.17485827.1999.tb03118.x

Giannelli A, Capelli G, Joachim A, Hinney B, Losson B, Kirkova Z and Brianti E (2017). Lungworms and gastrointestinal parasites of domestic cats: a European perspective. International Journal for Parasitology, 47(9): 517-528. DOI: https://doi.org/10.1016/j.ijpara.2017.02.003

Jalil DR and Alwan MJ (2014). Seropathological Diagnosis of Toxoplasma gondii in Stray Cats in Baghdad Province. Iraqi Journal of Veterinary Medicine, 38(1): 92- 98. Available at: http://jcovm.uobaghdad.edu.iq/index.php/Iraqijvm/article/view/260

Kennedy PC and Palmer N (2013). Pathology of domestic animals. Academic Press. DOI:https://doi.org/10.1016/b978-1-4832-32355.50004-7

Lee-Fowler T (2014). Feline respiratory disease: What is the role of Mycoplasma species?. Journal of Feline Medicine and Surgery, 16(7): 563-571. DOI:https://doi.org/10.1016/b978-1-4832-3235-5.50003-5

Lopez A and Martinson SA (2017). Respiratory System, Mediastinum, and Pleurae. In: J. F. Zachary (Editor), Pathologic Basis of Veterinary Disease, 6th Edition, Mosby, pp. 471-560. DOI: https://doi.org/10.1016/b978-0-323-35775-3.00009-6

Löhr CV, DeBess EE, Baker RJ, Hiett SL, Hoffman KA, Murdoch VJ, Fischer KA, Mulrooney DM, Selman RL and Hammill-Black WM (2010). Pathology and viral antigen distribution of lethal pneumonia in domestic cats due to pandemic (H1N1) 2009 influenza A virus. Veterinary Pathology, 47(3):378-86. DOI:https://doi.org/10.1177/0300985810368393

Luna LG (1968). Manual of histologic staining methods of the armed forces institute of pathology.34th ed. McGrow-Hill book company. New York. DOI:https://doi.org/10.1016/s0031-3025(16)39410-7

Maxie G (2016). Jubb, Kennedy \& Palmer's Pathology of Domestic Animals-E-Book (Vol. 2). Elsevier Health Sciences. DOI:https://doi.org/10.1016/b978-0-7020-5317-7.00021-7

McGregor GF, Sheehan K and Simko E (2016). Pneumonia and gastritis in a cat caused by feline herpesvirus-1. The Canadian $\begin{array}{lllll}\text { Veterinary } & \text { Journal, } & \text { 57(2): } & \text { Available }\end{array}$ https://www.ncbi.nlm.nih.gov/pubmed/?term=Pneumonia+and+gastritis+in+a+cat+caused+by+feline+herpesvirus-1

Mexas AM, Hess RS, Hawkins EC and Martin LD (2006). Pulmonary lesions in cats with diabetes mellitus. Journal of Veterinary Internal Medicine, 20(1): 47-51. DOI:https://doi.org/10.1111/j.1939-1676.2006.tb02822.x

Mohammed B, Amina D, Guetaf H and Boudjema B (2017). Air pollution from diesel particles and chronic obstruction pulmonary disease-CT scan study. European Scientific Journal, 13(6): 504. DOI:https://doi.org/10.19044/esj.2017.v13n6p504

Monne Rodriguez J, Köhler K and Kipar A (2018). Calicivirus co-infections in herpesvirus pneumonia in kittens. Veterinary Journal, 236:1-3. DOI:https://doi.org/10.1016/j.tvj1.2018.04.004

Nelson RW and Couto CG (2008). Small Animal Internal Medicine-E-Book. Elsevier Health Sciences. DOI:https://doi.org/10.1016/b978-1-4160-3949-5.50022-4

Niessen SJM, Hazuchova K, Powney SL, Guitian J, Niessen APM, Pion PD, Shaw JA and Church DB (2017). The Big Pet Diabetes Survey: Perceived Frequency and Triggers for Euthanasia. Veterinary Sciences, 4(2):27. DOI: https://doi.org/10.3390/vetsci4020027

Pimenta P, Alves-Pimenta S, Barros J, Pereira MJ, Maltez L, Maduro AP and Coelho AC (2015). Blepharitis due to Cryptococcus neoformans in a cat from northern Portugal. Journal of Feline Medicine and Surgery, Open Reports, 1(2): 2055116915593963. DOI: https://doi.org/10.1177/2055116915593963

Sykes JE (2013). Canine and feline infectious diseases. Elsevier Health Sciences. Available at: https://www.elsevier.com/books/canine-and-feline-infectious-diseases/sykes/978-1-4377-0795-3 
Thawley VJ and Drobatz KJ (2015). Assessment of dexmedetomidine and other agents for emesis induction in cats: 43 cases (20092014). Journal of the American Veterinary Medical Association, 247(12):1415-8. DOI https://doi.org/10.2460/javma.247.12.1415

Trivedi SR, Malik R, Meyer W and Sykes JE (2011). Feline cryptococcosis: impact of current research on clinical management. Journal of Feline Medicine and Surgery, 13(3): 163-172. DOI: https://doi.org/10.1016/j.jfms.2011.01.009

Wallig MA, Bolon B, Haschek WM, and Rousseaux CG (2017). Fundamentals of toxicologic pathology. Academic Press. Available at: https://www.elsevier.com/books/fundamentals-of-toxicologic-pathology/wallig/978-0-12-809841-7

White ES, Lazar MH and Thannickal VJ (2003). Pathogenetic mechanisms in usual interstitial pneumonia/idiopathic pulmonary fibrosis. The Journal of Pathology, 201(3): 343-354. DOI: https://doi.org/10.1002/path.1446 